\title{
Associations of cardiovascular risk factors, carotid intima-media thickness and manifest atherosclerotic vascular disease with carpal tunnel syndrome
}

\author{
Rahman Shiri ${ }^{1 *}$, Markku Heliövaara ${ }^{2}$, Leena Moilanen ${ }^{3}$, Jorma Viikari ${ }^{4}$, Helena Liira ${ }^{5,6}$ and Eira Viikari-Juntura ${ }^{1}$
}

\begin{abstract}
Background: The role of atherosclerosis in carpal tunnel syndrome (CTS) has not previously been addressed in population studies. The aim of this study was to investigate the associations of cardiovascular risk factors, carotid artery intima-media thickness (IMT), and clinical atherosclerotic diseases with CTS.

Methods: In this cross sectional study, the target population consisted of subjects aged 30 or over who had participated in the national Finnish Health Survey in 2000-2001. Of the 7977 eligible subjects, 6254 (78.4\%) were included in our study. Carotid IMT was measured in a sub-sample of subjects aged 45 to 74 ( $N=1353)$.

Results: Obesity (adjusted odds ratio (OR) 2.4, 95\% confidence interval (CI) 1.1-5.4), high LDL cholesterol (OR 3.8, $95 \% \mathrm{Cl} 1.6-9.1$ for $>190$ vs. $<129 \mathrm{mg} / \mathrm{dL}$ ), high triglycerides (OR 2.7, 95\% Cl 1.2-6.1 for $>200 \mathrm{vs.}<150 \mathrm{mg} / \mathrm{dL}$ ), hypertension (OR 3.4, 95\% Cl 1.6-7.4) and cardiac arrhythmia (OR 10.2, 95\% Cl 2.7-38.4) were associated with CTS in subjects aged 30-44. In the age group of 60 years or over, coronary artery disease (OR 1.9, 95\% Cl 1.1-3.5), valvular heart disease (OR 2.3, 95\% Cl 1.0-5.0) and carotid IMT (1.4, 95\% Cl 0.9-2.1 for each 0.23 mm increase) were associated with CTS. Carotid IMT was associated with CTS only in subjects with hypertension or clinical atherosclerotic vascular disease, or in those who were exposed to physical workload factors.

Conclusions: Our findings suggest an association between CTS and cardiovascular risk factors in young people, and carotid IMT and clinical atherosclerotic vascular disease in older people. CTS may either be a manifestation of atherosclerosis, or both conditions may share similar risk factors.
\end{abstract}

Keywords: Atherosclerosis carotid artery, coronary artery disease, hypertension, obesity, smoking, wrist

\section{Background}

Carpal tunnel syndrome (CTS) is the most common nerve entrapment $[1,2]$. It can cause major work disability and incur considerable costs to society [3]. Epidemiological studies have reported a higher risk of CTS among women than among men [1,4-6]. It is common in the third trimester of pregnancy, and in cases of hypothyroidism $[7,8]$ and renal disease [9]. Among men $[4,5,10]$ and women $[4,10]$, the age distribution of CTS

\footnotetext{
* Correspondence: rahman.shiri@ttl.fi

${ }^{1}$ Centre of Expertise for Health and Work Ability, Finnish Institute of Occupational Health, Helsinki, Finland

Full list of author information is available at the end of the article
}

is bimodal, with a peak between the ages of 50 and 59 and a second peak among those aged 70 or over.

Symptoms of CTS may appear when there is edema in the carpal tunnel, the volume of the contents of the tunnel is increased, the vulnerability of the nerve is increased, or the blood supply of the nerve is impaired. Endothelial damage may increase vascular permeability and cause edema in the carpal tunnel [11,12]. Increased interstitial fluid pressure in the carpal tunnel causes compression of the carpal tunnel contents, especially the median nerve. This may lead to poor blood circulation in the flexor synovial cells and the median nerve. Histological studies have shown edema, vascular sclerosis and fibrous tissue in the flexor tenosynovium $[13,14]$.
C Biomed Central

() 2011 Shiri et al; licensee BioMed Central Ltd. This is an Open Access article distributed under the terms of the Creative Commons Attribution License (http://creativecommons.org/licenses/by/2.0), which permits unrestricted use, distribution, and reproduction in any medium, provided the original work is properly cited. 
Conditions that may increase the vulnerability of the median nerve include diabetes $[7,8,15]$, renal disease [9], smoking [16-18] and the toxic effects of alcohol [19]. Impairment of vascular supply may increase the vulnerability of the nerve to mechanical loads, and prolonged tissue ischemia can lead to degeneration of the nerve and intraneural fibrosis $[12,20]$. Tenosynovitis of the finger flexor tendons is the most common cause for increases in the contents of the carpal tunnel. It occurs commonly in rheumatoid arthritis [21] and as a result of high physical workload exposure [22]. Mechanical stress may play a greater role among young rather than old people [6]. In contrast, ischemia caused by cardiovascular diseases or atherosclerosis may play a major role among elderly people.

Some evidence exists on the role of atherosclerosis risk factors such as obesity, smoking, LDL cholesterol and metabolic syndrome in CTS [16,17,23-27]. However, there is no evidence so far to support an association between atherosclerosis and CTS. In this study, we investigated the associations of atherosclerosis risk factors, carotid intima-media thickness (IMT), a surrogate marker of early atherosclerosis, and clinical atherosclerotic diseases with CTS. We hypothesized that atherosclerosis plays a larger role in the pathogenesis of CTS among older people rather than among younger individuals. The higher prevalence of CTS among elderly people - the second peak of the bimodal age distribution of CTS - may be due to atherosclerotic vascular disease. Moreover, we hypothesized that the presence of atherosclerotic disease increases the vulnerability of the median nerve to mechanical stress due to physical exposures.

\section{Methods}

\section{Population}

In the national health examination survey, Health 2000, the target population comprised men and women aged 30 or over residing in Finland between the fall of 2000 and the spring of 2001 [6]. To obtain a representative sample of the whole Finnish population, a two-stage stratified cluster sampling design was used and sample stratified according to the five university hospital regions, each containing roughly one million inhabitants. From each university hospital region, 16 health care districts were sampled as clusters.

The purpose of this survey was to provide up-to-date information on major public health problems in Finland, their causes and treatment, as well as functional capacity and work ability [28]. Information was gathered by means of interview and clinical health examination. At the comprehensive health examination, specially trained nurses carried out a symptom interview on cardiovascular and musculoskeletal complaints, and physicians performed a standardized physical examination, which included assessing the status of the upper extremity.

The original sample consisted of 8028 subjects aged 30 or over. Of these, 51 died before the interview, 6986 (87.6\%) were interviewed, and 6354 (79.7\%) participated in the health examinations. Subjects with missing CTS information $(\mathrm{n}=100)$ were excluded, leaving 6254 (78.4\%) subjects eligible for the analysis [6].

The Ethical Committee of Epidemiology and National Welfare of the Helsinki University Hospital District approved the Health 2000 survey on the $21^{\text {st }}$ of September 1999. All participants gave their informed consent.

\section{Outcome}

The diagnosis of possible CTS was based on 1) possible or classic/probable Katz hand diagrams (pain or paraesthesia or decreased sensitivity present in the thumb or index or middle finger during the preceding seven days), plus 2) either a positive Tinel's test result, combined wrist flexion and carpal compression, decreased sensation in the median nerve distribution, or weakness of thumb abduction or wasting of the thenar eminence [29]. A probable case of CTS was defined as a classic/ probable Katz hand diagram (symptoms in two of the three radial fingers), and positive findings in at least two of the four clinical tests. We also gathered information regarding surgery due to CTS.

\section{Determinants}

\section{Atherosclerosis risk factors}

Smoking status was assessed by a home interview and the subjects were defined as 1) current smokers if they smoked cigarettes, cigars or a pipe at the time of the interview; 2) former smokers if they had smoked for at least one year in the past and were not current smokers; 3) occasional smokers; and 4) never smokers. For current smokers, pack years were estimated and grouped into three levels $(<10,10-20,>20)$. Leisure-time physical activity was assessed by a single global question; "How often do you exercise so that you are short of breath or sweating?" We classified physical activity into three levels: $\leq 1,2-3$, and $\geq 4$ times per week.

Weekly consumption of alcohol was recorded in units (drinks, serving portions) and converted into grams of absolute alcohol. Alcohol consumption was grouped into 4 levels, none (0 grams of alcohol), light, moderate, or heavy (the three latter were based on tertiles of the distribution).

Height, weight, waist circumference and hip circumference were measured. Body mass index (BMI) was classified into underweight (BMI $\left.<18.5 \mathrm{~kg} / \mathrm{m}^{2}\right)$, normal weight (BMI 18.5-24.9 $\mathrm{kg} / \mathrm{m}^{2}$ ), overweight (BMI 25-29.9 $\mathrm{kg} / \mathrm{m}^{2}$ ) and obesity (BMI $\geq 30 \mathrm{~kg} / \mathrm{m}^{2}$ ). Waist circumference was grouped into three levels; for men $<94 \mathrm{~cm}, 94$ - 
$101.9 \mathrm{~cm}$, and $\geq 102 \mathrm{~cm}$, and for women $<80 \mathrm{~cm}, 80-87.9$ $\mathrm{cm}$ and $\geq 88 \mathrm{~cm}$. Waist-to-hip ratio was classified into three groups: for men $<0.9,0.9-1.0$, and $>1.0$, and for women $<0.8,0.8-0.9$, and $>0.9$.

The diagnosis of hypertension was based on a systolic blood pressure of $\geq 140 \mathrm{~mm} \mathrm{Hg}$ or a diastolic blood pressure of $\geq 90 \mathrm{~mm} \mathrm{Hg}$, or a previous diagnosis of hypertension together with the use of blood pressure lowering medication. The diagnosis of diabetes was based on elevated fasting blood glucose, and/or a known previous diagnosis of diabetes, or glucose lowering medication.

Fasting blood samples were collected for the analysis of serum glucose, insulin, cholesterol, and triglycerides. We defined metabolic syndrome according to the criteria of the American Association of Clinical Endocrinologists [30], i.e. when at least three of the following criteria were present: 1) Central obesity, defined as waist circumference $>102 \mathrm{~cm}$ for men and $>88 \mathrm{~cm}$ for women; 2) high fasting triglycerides, defined as $\geq 151 \mathrm{mg} / \mathrm{dl}$; 3) low high-density lipoprotein cholesterol defined as $<40$ $\mathrm{mg} / \mathrm{dl}$ for men and $<50 \mathrm{mg} / \mathrm{dl}$ for women; 4) elevated blood pressure, defined as a systolic blood pressure of $\geq 130 \mathrm{~mm} \mathrm{Hg}$ or a diastolic blood pressure of $\geq 85 \mathrm{~mm}$ $\mathrm{Hg}$; and 5) impaired fasting glucose, defined as a fasting glucose of $\geq 110 \mathrm{mg} / \mathrm{dl}$. The homeostasis model assessment of insulin resistance was defined as serum insulin $\times$ glucose/22.5. High-sensitive serum $C$-reactive protein was defined as $\geq 3 \mathrm{mg} / \mathrm{l}$.

\section{Atherosclerotic diseases}

Information on cardiovascular diseases was obtained through interview and clinical examination. The diagnosis of coronary artery disease was based on a physician ascertained diagnosis of previous angina pectoris, myocardial infarction, coronary angioplasty or a by-pass operation. The diagnosis of cerebrovascular disease was based on a history of previous stroke or a transient ischemic attack. Other heart or vascular diseases were heart failure, cardiac arrhythmia, valvular disease, or intermittent claudication, and the diagnoses were based on history.

\section{Carotid artery intima-media thickness}

Earlier [31] we described the details of ultrasound measures of carotid artery intima-media thickness (IMT). Ultrasound measures of carotid IMT were performed in a sub-sample of men and women aged 45 to 74 who resided within 200 kilometers of the six study clinics that had cardiovascular ultrasound equipment with a linear array transducer available. The six study clinics covered six Finnish towns and their surrounding areas (Helsinki, Turku, Tampere, Kuopio, Joensuu, and Oulu). Subjects $(\mathrm{N}=1867)$ who fulfilled these eligibility criteria were invited and 1526 (82\%) of them participated in the carotid artery ultrasound study. We assessed the relation between IMT and CTS among 1353 (72\%) subjects whose data on both carotid artery ultrasound and CTS was available.

A high-resolution B-mode carotid ultrasound examination of the right carotid artery was performed first on the distal $1 \mathrm{~cm}$ of the common carotid artery and then on the carotid artery bulb. The IMT was measured from three digitized end diastole images of the common carotid artery (lateral angle) and the carotid bulb (three interrogation angles). We used an average of these six measures in the analysis of this study.

\section{Covariates}

The home interview elicited information on age, gender, years of education, and work-related physical load factors. The presence of the following physical exposures in the current job was elicited (frequency or duration per day); working with hands above the shoulder plane, manual handling of loads over $5 \mathrm{~kg}$, manual handling of loads over $20 \mathrm{~kg}$, working with a vibrating tool, work demanding high handgrip forces, and repetitive movements of the hands or wrists [6]. In our previous report [6] we showed that in the presence of all physical load factors in the model, only high handgrip forces for at least one hour and using vibrating tools for at least two hours were associated with CTS. Therefore in the current study we controlled the obtained odds ratios of CTS for high handgrip forces and using vibrating tools.

The presence of somatization was assessed using the 13-item somatization part of Symptom Check List-90 [32]. We excluded three questions on pain and scored the remaining 10 items on a five-point Likert scale. The total score for each subject ranged from 0 to 40, with higher scores reflecting higher levels of somatization. In our earlier report, we tested a range of psychological and psychosocial factors. In the presence of all these factors we found an association with somatisation only. We therefore controlled for only this factor.

\section{Statistical methods}

The statistical significance level was set at $\mathrm{P}<0.05$. We adjusted P-values for multiple testing using Bonferroni correction and set statistical significance level at P-value $\leq 0.003$ for 15 subgroup analyses. Logistic regression models were run to study the associations of atherosclerosis risk factors, carotid IMT, and clinical vascular diseases with CTS. We used three outcomes (possible and probable CTS combined, probable CTS, surgery due to CTS) to take into consideration the severity of the disorder and the likelihood of correct diagnosis. We performed survey data analysis by using Stata's $s v y$ prefix command. Survey data analysis considers the weighting, clustering, and stratification of the survey design to correct imbalances in the probabilities of selection and to estimate the right standard errors. Stata's default svy 
variance estimator, the linearized variance estimator, was used to compute standard errors [33]. In the nonsurvey data analysis, this variance estimator refers to as the robust variance estimator. Confidence intervals were calculated based on the number of observations in the specific group being analysed. Age (continuous), gender, years of education (continuous), somatization (continuous), high handgrip forces and using vibrating tools were included in the logistic regression models as confounders. Gender- and age-specific analyses were also carried out. Effect modification was studied using stratified analysis. Multiplicative interactions were tested by including product terms in the multivariable models between physical load factors, risk factors of atherosclerosis, carotid IMT (categorized into two groups using the median) and clinical atherosclerotic disease.

\section{Results}

\section{Background characteristics}

The mean age of the study population was 52 and $48 \%$ were men. One-fourth of the population was current smokers and the mean BMI was $26.2 \mathrm{~kg} / \mathrm{m}^{2}$ (Table 1). The most common cardiovascular diseases were hypertension and coronary artery disease. The mean carotid IMT was $0.93 \mathrm{~mm}$ (range $0.5-2.5 \mathrm{~mm}$ ). The prevalence of possible and probable CTS combined was $3.8 \%$, probable CTS $1.0 \%$, and operated CTS $1.3 \%$.

Men had higher BMI, waist circumference and carotid IMT and lower HDL cholesterol than women. They were more frequently smokers and more commonly had coronary artery disease and intermittent claudication compared to women. In contrast, hypertension, heart failure, somatization and CTS were more common among women than among men.

\section{Atherosclerosis risk factors and CTS}

After adjustment for potential confounders, current smoking was associated with possible and probable CTS combined (OR 2.1, 95\% 1.4-3.1) and probable CTS (OR 2.9, 95\% CI 1.3-6.4). Among current smokers, there was no dose-response relationship between the number of pack-years smoked and CTS (Table 2). BMI, waist circumference and high-sensitive C-reactive protein were associated with operated CTS only. Leisure-time physical activity, alcohol consumption, waistto-hip ratio, LDL and HDL cholesterol were not associated with CTS. Subjects with type 1 diabetes or metabolic syndrome had a higher prevalence of CTS than those without the condition. Furthermore, the prevalence of operated CTS was higher among subjects with high triglycerides, insulin resistance, or hypertension compared with those without such conditions. None of these associations, however, was statistically significant.
Table 1 Background characteristics of study subjects (weighted proportion or mean), Health 2000 Survey, 2000-2001.

\begin{tabular}{lcc}
\hline Characteristic & Mean (SD) & $\%(\mathbf{9 5 \%} \mathrm{Cl})$ \\
\hline Age (years) & $51.9(13.9)$ & \\
Years of education & $11.3(4.0)$ & \\
& & \\
Smoking status & \\
$\quad$ Former & $31(30-32)$ \\
$\quad$ Current & $26(24-27)$
\end{tabular}

\section{Weight-related}

Body mass index $\left(\mathrm{kg} / \mathrm{m}^{2}\right)$

Waist circumference $(\mathrm{cm}) \quad 93$ (13.3)

Hip circumference $(\mathrm{cm}) \quad 102(9.5)$

Serum lipids

LDL cholesterol (mg/dL) 148 (46)

HDL cholesterol (mg/dL) 52 (15)

Total cholesterol (mg/dL) 232 (44)

Metabolic factors

Metabolic syndrome

$30(29-32)$

Diabetes

$5.2(4.6-5.9)$

Hypertension

$20(18-21)$

Cardiovascular diseases

Coronary artery disease

$7.1(6.4-7.8)$

Heart failure

$1.7(1.3-2.0)$

Arrhythmia

$5.1(4.5-5.7)$

Valvular heart disease

$2.5(2.1-3.0)$

Cerebrovascular disease

$2.7(2.3-3.1)$

Intermittent claudication

$1.2(0.9-1.5)$

\section{Atherosclerosis}

Carotid intima-media thickness (mm) $0.93(0.23)$

Individual psychological factor

Somatization (score 0-40)

$6.7(5.8)$

Carpal tunnel syndrome

Possible or probable

$3.8(3.3-4.4)$

Probable

$1.0(0.7-1.3)$

Operated

$1.3(1.0-1.6)$

\section{Atherosclerotic disease and CTS}

Subjects with coronary artery disease, valvular heart disease, intermittent claudication, or cerebrovascular disease had a higher prevalence of possible and probable CTS combined (Table 3, Figure 1) or probable CTS (Table 3) compared with those without such a condition. However, none of these associations was 
Table 2 Adjusted odds ratios (OR) of carpal tunnel syndrome (CTS) according to cardiovascular risk factors.

\begin{tabular}{|c|c|c|c|c|c|c|c|c|c|c|}
\hline \multirow[t]{2}{*}{ Characteristic } & \multirow[t]{2}{*}{ Sample } & \multicolumn{3}{|c|}{ Possible and probable CTS combined } & \multicolumn{3}{|c|}{ Probable CTS } & \multicolumn{3}{|c|}{ Operated CTS } \\
\hline & & Cases & OR & $95 \% \mathrm{Cl}$ & Cases & OR & $95 \% \mathrm{Cl}$ & Cases & OR & $95 \% \mathrm{Cl}$ \\
\hline \multicolumn{11}{|l|}{ Smoking status } \\
\hline Never smoker & 2062 & 84 & 1 & & 20 & 1 & & 29 & 1 & \\
\hline Former smoker & 1649 & 51 & 1.2 & $0.8-1.6$ & 11 & 1.0 & $0.4-2.3$ & 15 & 1.0 & $0.5-1.8$ \\
\hline Occasional smoker & 333 & 9 & 1.2 & $0.5-2.6$ & 3 & 2.0 & $0.6-6.8$ & 5 & 2.4 & $0.9-6.3$ \\
\hline \multicolumn{11}{|l|}{ Current smoker } \\
\hline$<10$ pack-years & 501 & 26 & 2.0 & $1.2-3.5$ & 3 & 1.1 & $0.3-3.9$ & 6 & 1.4 & $0.5-3.7$ \\
\hline 10-20 pack-years & 400 & 26 & 2.6 & $1.5-4.4$ & 12 & 5.7 & $2.3-14.1$ & 6 & 1.8 & $0.6-4.7$ \\
\hline >20 pack-years & 429 & 19 & 1.7 & $0.9-3.1$ & 7 & 2.7 & $0.9-8.0$ & 6 & 1.5 & $0.6-3.7$ \\
\hline
\end{tabular}

Exercise (times/week)

$$
\begin{aligned}
& \leq 1 \\
& 2-3
\end{aligned}
$$$$
\geq 4
$$

Alcohol consumption

\section{None \\ Light}

Moderate

Excessive

Body mass index

Normal

Underweight

Overweight

Obese

\section{6}

68

69

1237

972

978

987

2514

61

2288

1002

Waist circumference

$$
\begin{aligned}
& \text { Normal } \\
& \text { Increased }
\end{aligned}
$$

Obese

Normal

Increased

Obese

$$
\geq 190
$$

\section{9}

$\geq 60$

40-60

$\leq 40$

1340

2487

Total cholesterol (mg/dL)

$$
\begin{aligned}
& >200 \\
& 200-239 \\
& \leq 240
\end{aligned}
$$

$\begin{array}{cc}77 & 1 \\ 119 & 0.8 \\ 47 & 0.8 \\ & \\ & \\ 45 & 1 \\ 91 & 1.4 \\ 107 & 1.4\end{array}$

$0.8-2.1$

$0.7-1.5$

$21 \quad 1$

$15 \quad 1.0$

$0.5-1.8$

0.8-1.6

$23 \quad 1.6$

0.9-3.0

29

$25 \quad 1.1 \quad 0.6-1.9$

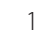

1.0

0.9

1.5

$0.6-1.6$

$0.5-1.5$

$0.8-2.7$

$\begin{array}{cccccc}19 & 1 & & 22 & 1 & \\ 5 & 0.6 & 0.2-1.7 & 9 & 0.9 & 0.3-2.2 \\ 8 & 1.1 & 0.4-2.8 & 7 & 0.8 & 0.3-2.0 \\ 6 & 1.1 & 0.4-2.9 & 8 & 1.3 & 0.5-3.3\end{array}$

$0.7-1.5$

$0.8-1.9$

18
0
20
19

1

1.1

$0.5-2.0$

$$
17
$$

11.9

$0.2-15.1$

1.3

$19 \quad 1.6$

$0.8-3.0$
$0.4-1.2$

$$
15 \quad 1
$$$$
\begin{array}{ll}
15 & 1 \\
9 & 0.6
\end{array}
$$

$0.7-1.6$

36

$36 \quad 1$

$0.2-1.8$

$0.5-2.1$

1.5-9.0

1.1

$0.7-2.2$

$\begin{array}{cccccc}5 & 1 & & 9 & 1 & \\ 29 & 1.3 & 0.5-3.2 & 38 & 0.9 & 0.4-2.2 \\ 26 & 1.6 & 0.6-4.4 & 31 & 1.4 & 0.5-3.2\end{array}$

1.3

0.8-1.7

$\begin{array}{ll}23 & 1\end{array}$

0.9-2.2

26
13

$13 \quad 1.0$

$0.4-1.2 \quad 38$

$1.1 \quad 0.6-1.9$

1.4

0.6-1.2

21

$0.5-1.2$

24
17

17

0.7

$0.3-1.2$

$\begin{array}{lll}36 & 0.9 & 0.5-1.7\end{array}$

$0.8 \quad 0.5-1.2$

$1.4 \quad 0.9-2.3$

$0.9-2.3$

15

$\begin{array}{llllll}18 & 0.8 & 0.4-1.8 & 27 & 1.5 & 0.7-3.0 \\ 29 & 1.1 & 0.5-2.2 & 40 & 1.8 & 0.9-3.6\end{array}$




\begin{tabular}{|c|c|c|c|c|c|c|c|c|c|c|}
\hline \multicolumn{11}{|l|}{ Triglycerides (mg/dL) } \\
\hline$\leq 150$ & 4186 & 163 & 1 & & 39 & 1 & & 46 & 1 & \\
\hline 151-199 & 1069 & 42 & 0.8 & $0.6-1.1$ & 13 & 1.0 & $0.5-1.8$ & 16 & 1.1 & $0.5-2.3$ \\
\hline$\geq 200$ & 981 & 38 & 1.0 & $0.6-1.5$ & 10 & 1.0 & $0.4-2.3$ & 17 & 1.7 & $0.9-3.1$ \\
\hline \multicolumn{11}{|c|}{ High-sensitive C-reactive protein } \\
\hline Low ( $\leq 3$ mg/L) & 5117 & 195 & 1 & & 46 & 1 & & 54 & 1 & \\
\hline High (>3 mg/L) & 1062 & 47 & 0.9 & $0.6-1.3$ & 16 & 1.2 & $0.6-2.3$ & 25 & 1.7 & $1.1-2.8$ \\
\hline \multicolumn{11}{|c|}{ Insulin resistance (tertile) } \\
\hline $1^{\text {st }}$ & 2077 & 68 & 1 & & 18 & 1 & & 18 & 1 & \\
\hline $2^{\text {nd }}$ & 2072 & 83 & 1.0 & $0.7-1.4$ & 17 & 0.8 & $0.4-1.5$ & 24 & 1.2 & $0.7-2.2$ \\
\hline $3^{\text {rd }}$ & 2083 & 92 & 1.1 & $0.8-1.6$ & 27 & 1.1 & $0.6-1.9$ & 37 & 1.7 & $0.9-3.3$ \\
\hline \multicolumn{11}{|l|}{ Metabolic syndrome } \\
\hline No & 4313 & 145 & 1 & & 32 & 1 & & 41 & 1 & \\
\hline Yes & 1902 & 96 & 1.1 & $0.8-1.5$ & 30 & 1.6 & $0.98-2.6$ & 36 & 1.5 & $0.9-2.5$ \\
\hline \multicolumn{11}{|l|}{ Diabetes } \\
\hline No & 5880 & 222 & 1 & & 55 & 1 & & 71 & 1 & \\
\hline Type 1 & 34 & 2 & 1.9 & $0.4-8.5$ & 1 & 3.5 & $0.4-29.0$ & 1 & - & - \\
\hline Type 2 & 319 & 19 & 1.0 & $0.5-1.8$ & 6 & 1.2 & $0.4-3.5$ & 7 & 1.1 & $0.5-2.6$ \\
\hline \multicolumn{11}{|l|}{ Hypertension } \\
\hline No & 5017 & 174 & 1 & & 43 & 1 & & 52 & & \\
\hline Yes & 1237 & 69 & 1.2 & $0.8-1.6$ & 19 & 1.2 & $0.6-2.1$ & 27 & 1.6 & $0.9-2.7$ \\
\hline
\end{tabular}

A separate model was run for each characteristic and the odds ratios obtained were adjusted for age, sex, education, somatization, handgrip with high forces and work using vibrating tools

statistically significant. Carotid IMT was associated with an increased prevalence of CTS; the odds ratio (OR) was only statistically significant for probable CTS (OR 1.7, 95\% CI 1.1-2.6 for each standard deviation $(0.23$ $\mathrm{mm}$ ) increase in IMT). Heart failure and arrhythmia were not associated with CTS. Subjects with coronary artery disease were less likely to be operated on for CTS than those without such a condition.

\section{Age-specific analyses}

\section{Possible and probable CTS combined}

BMI, waist-to-hip ratio, LDL cholesterol, triglycerides, hypertension, and arrhythmia were associated with possible and probable CTS combined in subjects aged 3044 (Table 4$)$. In the age group of 60 years or over, leisure-time physical activity, coronary artery disease, and valvular heart disease were associated with CTS. The association between current smoking and CTS was only statistically significant in subjects aged 45-59. Alcohol consumption, C-reactive protein, metabolic syndrome, and insulin resistance were not associated with CTS in any age group.

\section{Probable CTS}

The results remained consistent using probable CTS as outcome. The prevalence of probable CTS increased two-fold (OR 2.1, 95\% CI 1.4-3.1) for each standard deviation increase in IMT for subjects aged 60-74. The association was weak and non-significant among those aged 45-59 (OR 1.4, 95\% CI 0.9-2.1). The prevalence of probable CTS was higher among subjects with vascular disease (coronary artery disease, cerebrovascular disease or intermittent claudication) aged 50 or over, and among subjects with hypertension aged 30-39 or over 70 , compared with those without such a condition (data not shown).

\section{Operated CTS}

Metabolic syndrome, C-reactive protein, LDL and HDL cholesterol, and insulin resistance were associated with operated CTS only in subjects aged 45-59 (data not shown). BMI was associated with CTS among subjects aged 30-44 as well as among those aged 45-59. Former smoking and physical activity were associated with operated CTS among those aged 60 or over. Among subjects with hypertension, operated CTS had a bimodal age 
Table 3 Adjusted odds ratios (OR) of carpal tunnel syndrome (CTS) according to vascular disease and carotid intimamedia thickness.

\begin{tabular}{|c|c|c|c|c|c|c|c|c|c|c|}
\hline \multirow[t]{2}{*}{ Cardiovascular disease } & \multirow[t]{2}{*}{ Sample } & \multicolumn{3}{|c|}{$\begin{array}{c}\text { Possible and probable CTS } \\
\text { combined }\end{array}$} & \multicolumn{3}{|c|}{ Probable CTS } & \multicolumn{3}{|c|}{ Operated } \\
\hline & & Cases & OR & $95 \% \mathrm{Cl}$ & Cases & OR & $95 \% \mathrm{Cl}$ & $\overline{\text { Cases }}$ & OR & $95 \% \mathrm{Cl}$ \\
\hline \multicolumn{11}{|l|}{ Coronary artery disease } \\
\hline No & 5774 & 209 & 1 & & 52 & 1 & & 75 & & \\
\hline Yes & 480 & 34 & 1.3 & $0.7-2.2$ & 10 & 1.5 & $0.6-3.4$ & 4 & 0.3 & $0.1-0.9$ \\
\hline \multicolumn{11}{|l|}{ Intermittent claudication } \\
\hline No & 6175 & 237 & 1 & & 60 & 1 & & 78 & 1 & \\
\hline Yes & 79 & 6 & 1.4 & $0.5-3.6$ & 2 & 2.1 & $0.4-9.0$ & 1 & 0.4 & $0.1-2.7$ \\
\hline \multicolumn{11}{|l|}{ Cerebrovascular disease } \\
\hline No & 6073 & 230 & 1 & & 56 & 1 & & 78 & 1 & \\
\hline Yes & 181 & 13 & 1.2 & $0.5-2.4$ & 6 & 2.4 & $0.8-7.1$ & 1 & 0.3 & $0.1-2.3$ \\
\hline \multicolumn{11}{|l|}{ Heart failure } \\
\hline No & 6126 & 230 & 1 & & 59 & 1 & & 77 & 1 & \\
\hline Yes & 128 & 13 & 1.2 & $0.5-2.7$ & 3 & 1.1 & $0.3-4.2$ & 2 & 0.6 & $0.1-2.6$ \\
\hline \multicolumn{11}{|l|}{ Arrhythmia } \\
\hline No & 5916 & 221 & 1 & & 56 & 1 & & 75 & 1 & \\
\hline Yes & 338 & 22 & 1.0 & $0.6-1.8$ & 6 & 1.2 & $0.4-3.4$ & 4 & 0.6 & $0.2-1.9$ \\
\hline \multicolumn{11}{|l|}{ Valvular heart disease } \\
\hline No & 6078 & 229 & 1 & & 57 & 1 & & 77 & 1 & \\
\hline Yes & 176 & 14 & 1.6 & $0.7-3.4$ & 5 & 2.3 & $0.7-6.4$ & 2 & 0.7 & $0.1-3.2$ \\
\hline \multicolumn{11}{|l|}{ Carotid intima-media thickness } \\
\hline Mean IMT, per each standard deviation $(0.23 \mathrm{~mm})$ increase & 1353 & 55 & 1.3 & $0.99-1.8$ & 14 & 1.7 & $1.1-2.6$ & 16 & 1.4 & $0.9-2.2$ \\
\hline
\end{tabular}

A separate model was run for each characteristic and the odds ratios obtained were adjusted for age, sex, education, somatization, handgrip with high forces and work using vibrating tools

distribution with a first peak in those aged 50-59 and a second peak in those aged 70-79.

\section{Gender-specific analyses}

In gender-specific analyses, the associations of atherosclerosis risk factors with possible and probable CTS combined did not differ between men and women. After adjustment for potential confounders, carotid IMT was associated with possible and probable CTS combined (OR 1.7, 95\% CI 1.1.2.6 for each $0.23 \mathrm{~mm}$ increase), probable CTS (OR 2.2, 95\% CI 1.2-4.0), and operated CTS (OR 2.3, 95\% CI 1.1-4.8) among men only.

\section{Effect modification}

In subjects aged 30-44, stratified analyses controlled for potential confounders showed that high LDL cholesterol, high triglycerides, hypertension, and insulin resistance were associated with CTS in overweight or obese subjects, but not in normal-weight subjects (Table 5). Mean BMI did not differ in overweight/obese subjects with an LDL of $>130$ vs. $\leq 129$ (28.9 vs. $\left.28.6 \mathrm{~kg} / \mathrm{m}^{2}\right)$. It was higher in overweight/obese subjects with triglycerides of $>150$ vs. $<150$ (29.6 vs. $\left.28.2 \mathrm{~kg} / \mathrm{m}^{2}\right)$, overweight/ obese subjects with vs. without hypertension (30.9 vs. $28.6 \mathrm{~kg} / \mathrm{m}^{2}$ ), and in overweight/obese subjects with high vs. low insulin resistance ( 29.7 vs. $\left.27.4 \mathrm{~kg} / \mathrm{m}^{2}\right)$. Among subjects aged 60 or over, the association of vascular disease with CTS was independent of BMI level.

After adjustment for age, gender and education, carotid IMT was only associated with possible and probable CTS combined in subjects with hypertension (OR 1.6, 95\% CI 1.1-2.4 for each $0.23 \mathrm{~mm}$ increase in IMT), and not in those with normal blood pressure. This association did not differ between men (OR 1.6, 95\% CI 0.92.6) and women (OR 1.6, 95\% CI 0.8-2.8). Furthermore, carotid IMT was associated with possible and probable CTS combined only in subjects with vascular disease (coronary artery disease, intermittent claudication or cerebrovascular disease) (OR 2.1, 95\% CI 1.1-4.0). Finally, carotid IMT was associated with CTS only 


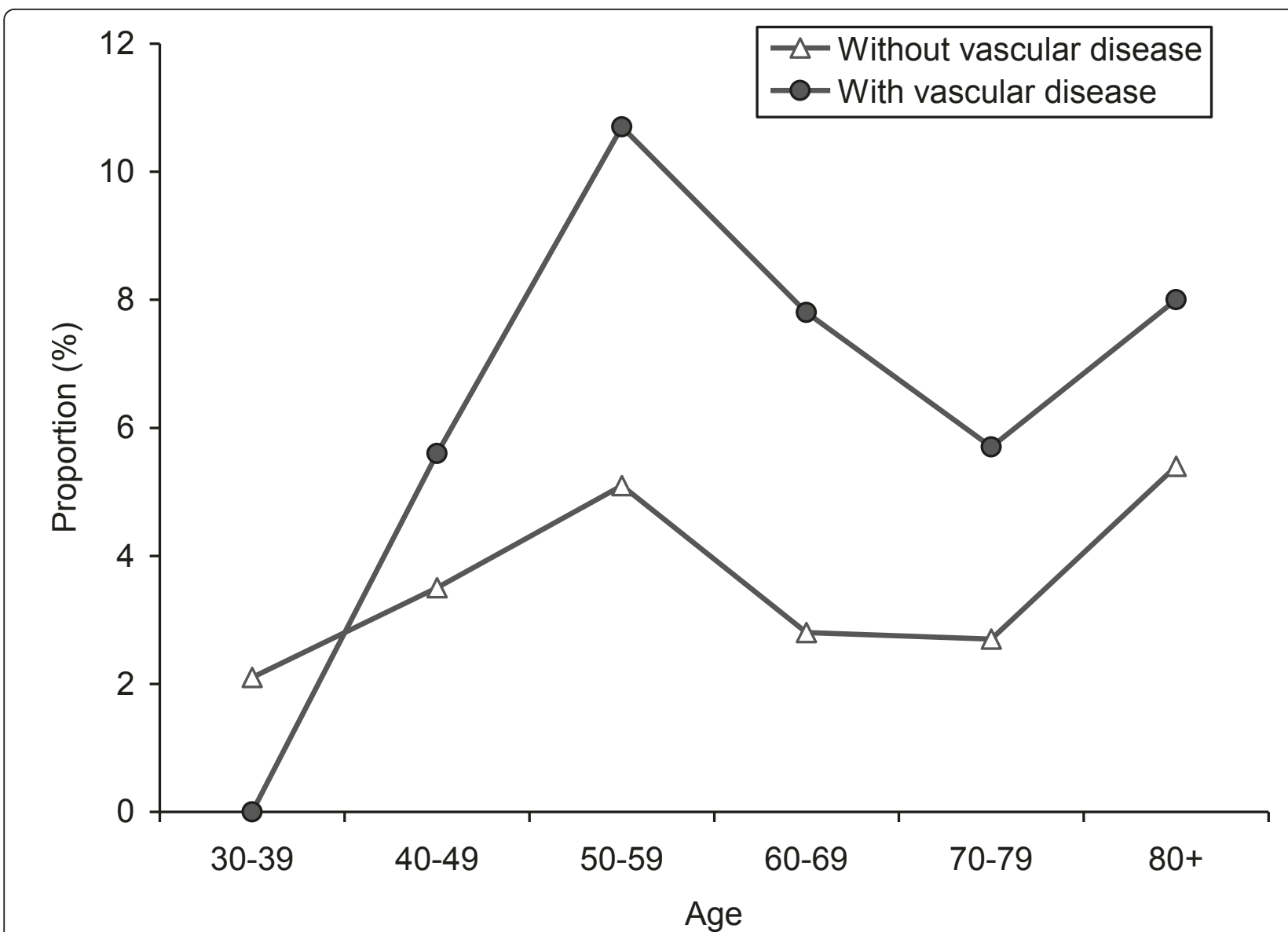

Figure 1 Age-specific prevalence of possible and probable carpal tunnel syndrome combined according to vascular disease (coronary artery disease, cerebrovascular disease, or intermittent claudication). The difference in prevalence between the two groups was statistically significant for the 50-59, 60-69 and 70-79 year age groups.

among subjects who were exposed to physical workload factors (Table 6). The odds ratio was 1.5 (95\% CI 1.0 -2.2) for subjects exposed to handgrip with high forces, 2.1 (95\% CI 1.2-3.7) for those exposed to manual handling of loads over $20 \mathrm{~kg}$, and 2.6 (95\% CI 1.4-4.8) for subjects exposed to both high handgrip forces and manual handling of loads over $20 \mathrm{~kg}$.

There was no interaction between smoking and obesity, between smoking and physical workload factors, and between obesity and physical workload factors.

\section{Discussion}

Our findings showed that obesity, dyslipidemia, and hypertension are associated with CTS in people aged 30-44, while coronary artery disease and carotid IMT are associated with CTS in those aged 60 or over. An association between carotid IMT and CTS was found only in subjects exposed to physical load factors and in those with hypertension or atherosclerotic disease. Our study [10] is in line with other studies [4,5] showing a bimodal age distribution for CTS among men $[4,5]$ and women [4], which may partly be due to atherosclerosis and its risk factors.

The aetiology of CTS is multifactorial. Some studies have shown associations between cardiovascular risk factors such as obesity, smoking, LDL cholesterol and metabolic syndrome, and CTS [16,17,23-27]. We found associations of atherosclerosis risk factors with CTS in young adults. Other studies [24,34] have also reported a stronger association of obesity with CTS in younger than older subjects. Overweight/obesity with hypertension or metabolic disturbances such as dyslipidemia and insulin resistance may play a role in CTS among young adults. Subjects with hypertension or dyslipidemia are more likely to have a higher BMI than those with normal blood pressure or normal serum lipid levels. Moreover, for women, hormonal factors may also play a role in CTS [8]. Therefore, the associations of hypertension, LDL cholesterol and triglycerides with CTS could be confounded by BMI, oral contraceptive use, or hormone replacement therapy. However, in the current study, after further adjustment for BMI (both in total population and in women) and history 
Table 4 Age-specific adjusted odds ratio of possible and probable carpal tunnel syndrome combined, Health 2000 survey, 2000-2001.

\begin{tabular}{|c|c|c|c|c|c|c|c|c|c|c|c|c|}
\hline \multirow[t]{2}{*}{ Characteristic } & \multicolumn{4}{|c|}{$30-44$ yrs $(N=2132)$} & \multicolumn{4}{|c|}{$45-59$ yrs $(\mathrm{N}=2190)$} & \multicolumn{4}{|c|}{$60+\operatorname{yrs}(N=1932)$} \\
\hline & Sample & Cases & OR & $95 \% \mathrm{Cl}$ & Sample & Cases & OR & $95 \% \mathrm{Cl}$ & Sample & Cases & OR & $95 \%$ \\
\hline \multicolumn{13}{|l|}{ Smoking status } \\
\hline Never smoker & 522 & 9 & 1 & & 593 & 29 & 1 & & 947 & 46 & 1 & \\
\hline Former smoker & 465 & 8 & 0.9 & $0.3-2.4$ & 649 & 23 & 1.0 & $0.6-1.7$ & 535 & 20 & 1.6 & $0.9-3$. \\
\hline Occasional smoker & 194 & 3 & 0.8 & $0.2-3.2$ & 105 & 6 & 1.8 & $0.6-4.8$ & 34 & 0 & - & \\
\hline Current smoker & 601 & 22 & 1.8 & $0.8-3.6$ & 553 & 42 & 1.9 & $1.1-3.3$ & 193 & 8 & 1.8 & $0.7-4$ \\
\hline
\end{tabular}

Exercise (times/week)

\begin{tabular}{|c|c|c|c|c|c|c|c|c|c|c|c|c|}
\hline$\leq 1$ & 915 & 23 & 1 & & 916 & 45 & 1 & & 665 & 28 & 1 & \\
\hline $2-3$ & 775 & 16 & 0.8 & $0.4-1.6$ & 717 & 35 & 1.0 & $0.6-1.7$ & 481 & 17 & 1.2 & $0.6-2.4$ \\
\hline$>4$ & 427 & 9 & 0.9 & $0.4-1.8$ & 526 & 27 & 1.1 & $0.6-1.8$ & 668 & 33 & 1.7 & $1.0-2.7$ \\
\hline
\end{tabular}

Body mass index

Normal
Overweight
Obese

Waist circumference

Normal
Increased
Obese

Waist-hip ratio

Normal
Increased
Obese

Obese

LDL cholesterol (mg/dL)

$$
\begin{aligned}
& <129 \\
& 130-189 \\
& \geq 190
\end{aligned}
$$

HDL cholesterol $(\mathrm{mg} / \mathrm{dL})$

$$
>60
$$

$\leq 40$

Total cholesterol $(\mathrm{mg} / \mathrm{dL})$

$$
\begin{aligned}
& >200 \\
& 200-239 \\
& \leq 240
\end{aligned}
$$

$\begin{array}{ccc}1065 & 18 & 1 \\ 688 & 15 & 1.4 \\ 264 & 14 & 2.4\end{array}$

$0.7-2.7$

$1.1-5.4$

$\begin{array}{ccc}815 & 34 & 1 \\ 848 & 43 & 1.1 \\ 413 & 27 & 1.2\end{array}$

0.6-1.8

$0.6-2.2$

$\begin{array}{ccc}617 & 26 & 1 \\ 614 & 22 & 0.7 \\ 954 & 62 & 0.9\end{array}$

$0.3-2.2$

$\begin{array}{lll}562 & 9 & 0.8\end{array}$

$\begin{array}{lll}535 & 22 & 1.5\end{array}$

$0.8-2.9$

$\begin{array}{lll}484 & 4 & 1\end{array}$

$\begin{array}{lll}1271 & 32 & 2.7\end{array}$

$0.9-7.8$

281

1202

1.0-9.0

$\begin{array}{cc}11 & 1 \\ 64 & 1.5 \\ 35 & 1.1\end{array}$

$0.7-2.9$

$0.5-2.3$

$$
\begin{array}{lll}
357 & 13 & 3.0
\end{array}
$$

$\begin{array}{ccc}951 & 16 & 1 \\ 973 & 23 & 1.6 \\ 198 & 10 & 3.8\end{array}$

$0.8-3.2$

604

$\begin{array}{lll}604 & 28 & 1 \\ 1163 & 62 & 1.2\end{array}$

$1.6-9.1$

$\begin{array}{lll}419 & 20 & 1.1\end{array}$

$0.7-2.0$

$0.4-1.3$

$0.5-1.6$

$\begin{array}{ccc}590 & 15 & 1 \\ 1121 & 22 & 0.7 \\ 411 & 12 & 1.3\end{array}$

$0.3-1.4$

609

1129

$0.6-2.9$ $\begin{array}{ll}41 \quad 1 \\ 52 & 07\end{array}$

$\begin{array}{ll}52 & 0.7\end{array}$

$\begin{array}{lll}448 & 17 & 0.6\end{array}$

0.4-1.2

$0.3-1.0$

$\begin{array}{ccc}759 & 13 & 1 \\ 797 & 16 & 1.1 \\ 566 & 20 & 2.3\end{array}$

$0.4-2.5$

393

785

$0.97-5.5$

1008

$\begin{array}{lc}18 & 1 \\ 44 & 1.3 \\ 48 & 1.1\end{array}$

$0.6-2.5$

$0.5-2.2$

$0.5-2.3$

$$
\begin{array}{lll}
634 & 30 & 1
\end{array}
$$

$\begin{array}{lll}752 & 24 & 0.7\end{array}$

$\begin{array}{lll}325 & 17 & 0.7\end{array}$

$0.4-1.3$

$0.3-1.5$

387

$\begin{array}{lll}508 & 13 & 0.6\end{array}$

$0.2-1.2$

1020

$0.4-1.5$

$\begin{array}{ccc}157 & 9 & 1 \\ 1081 & 39 & 0.5\end{array}$

$\begin{array}{lll}676 & 33 & 0.7\end{array}$

$0.2-1.2$

$0.3-1.5$

Triglycerides (mg/dL)

$\leq 150$
$151-199$
$>200$

$\begin{array}{ccc}517 & 25 & 1 \\ 996 & 40 & 0.8 \\ 415 & 19 & 0.8\end{array}$

$0.4-1.4$

415

0.4-1.6$$
>200
$$

$\begin{array}{ccc}1562 & 32 & 1 \\ 281 & 4 & 0.6 \\ 279 & 13 & 2.7\end{array}$

$0.2-1.8$

$\begin{array}{lll}1435 & 78 \quad 1\end{array}$

$\begin{array}{lll}395 & 21 & 0.8\end{array}$

0.5-1.3

490

$\begin{array}{ll}21 & 1\end{array}$

$\begin{array}{lll}957 & 45 & 1.2\end{array}$

$0.6-2.1$

$\begin{array}{lll}481 & 18 & 1.0\end{array}$

$0.4-2.2$

Hypertension

$\begin{array}{lcccccccccccc}\text { No } & 2028 & 41 & & & 1748 & 83 & & & 1241 & 50 & \\ \text { Yes } & 104 & 8 & 3.4 & 1.6-7.4 & 442 & 27 & 1.0 & 0.6-1.7 & 691 & 34 & 1.0 & 0.6-1.5\end{array}$


Table 4 Age-specific adjusted odds ratio of possible and probable carpal tunnel syndrome combined, Health 2000 survey, 2000-2001. (Continued)

\begin{tabular}{|c|c|c|c|c|c|c|c|c|c|c|c|c|}
\hline \multicolumn{13}{|l|}{ Coronary artery disease } \\
\hline No & 2127 & 49 & & & 2141 & 107 & & & 1506 & 53 & & \\
\hline Yes & 5 & 0 & - & - & 49 & 3 & 1.2 & $0.3-3.8$ & 426 & 31 & 1.9 & $1.1-3.5$ \\
\hline \multicolumn{13}{|l|}{ Heart failure } \\
\hline No & 2131 & 49 & & & 2184 & 109 & 1 & & 1811 & 72 & 1 & \\
\hline Yes & 1 & 0 & - & - & 6 & 1 & 2.0 & $0.2-15.0$ & 121 & 12 & 1.6 & $0.6-3.8$ \\
\hline \multicolumn{13}{|l|}{ Arrhythmia } \\
\hline No & 2118 & 47 & 1 & & 2118 & 103 & 1 & & 1680 & 71 & 1 & \\
\hline Yes & 14 & 2 & 10.2 & $2.7-38.4$ & 72 & 7 & 1.6 & $0.6-3.8$ & 252 & 13 & 0.8 & $0.4-1.8$ \\
\hline \multicolumn{13}{|l|}{ Valvular heart disease } \\
\hline No & 2122 & 49 & & & 2161 & 108 & & & 1795 & 72 & & \\
\hline Yes & 10 & 0 & - & - & 29 & 2 & 1.0 & $0.2-4.8$ & 137 & 12 & 2.3 & $1.0-5.0$ \\
\hline $\begin{array}{l}\text { Mean IMT, per each standard } \\
\text { deviation }(0.23 \mathrm{~mm}) \text { increase }\end{array}$ & & & & & 876 & 38 & 1.2 & $0.8-1.9$ & 477 & 17 & 1.4 & $0.9-2.1$ \\
\hline
\end{tabular}

A separate model was run for each characteristic and the odds ratios obtained were adjusted for age, sex, education, somatization, handgrip with high forces and work using vibrating tools

of oral contraceptive use or hormone replacement therapy (in women), these associations remained statistically significant in subjects aged 30-44 (data not shown). The use of oral contraceptives only slightly attenuated the association between triglycerides and CTS.

So far, there is no strong evidence to support an association between atherosclerosis and CTS. Carotid artery IMT is used as a surrogate marker of early atherosclerosis or a measure of asymptomatic atherosclerotic vascular disease [35]. We found a stronger association of carotid IMT with CTS in older than younger subjects. This may be due to the fact that atherosclerosis was more advanced among subjects aged 60-74. (Mean IMT 1.06, SD 0.25) than among those aged 45-59 (Mean IMT 0.87, SD 0.18). Moreover, there was an association between carotid IMT and CTS only in subjects with atherosclerotic vascular disease or in those exposed to physical load factors. In subjects with vascular disease, carotid IMT may also be associated with obliterative changes in arteries supplying the carpal tunnel contents. Impairment of vascular supply could render the median nerve more vulnerable to mechanical loads.

Ischemic endothelial damage leads to increased vascular permeability and increased interstitial fluid pressure $[11,12]$. This may render the median nerve vulnerable to damage especially when the oxygen demands of the carpal tunnel contents due to physical stress are increased. The ischemia of the median nerve produces neuronal edema and subsequently leads to intraneural fibrosis. The association between carotid IMT and CTS in those suffering from vascular disease may be related to the severity of such a disease. In other analyses, we found that subjects with a thicker carotid intima-media have several coexisting vascular diseases or risk factors (data not shown).

The advantages of the current study include a population-based sample with a high response rate, face-toface interviews, comprehensive physical examinations, laboratory tests, and the advanced imaging method. The study population was interviewed on two separate occasions and by different interviewers in order to gather information on both exposure history and musculoskeletal symptoms. Therefore, those who assessed exposures were not aware of musculoskeletal symptoms [28]. The limitations of this study are its crosssectional nature and its reliance on CTS diagnosed primarily by physical examination. We did not use nerve conduction studies to confirm the diagnosis of CTS. Considering nerve conduction studies as a golden standard test, a combination of a classic/probable hand diagram and either a positive Tinel's or Phalen's test result can correctly diagnose $79 \%$ of CTS cases [36]. Our prevalence estimate (3.8\%) was also close to those obtained in a Swedish population-based study [1] through a clinical examination $(3.8 \%)$ or electrodiagnostic measurements (4.9\%).

The results of subgroup analyses should be interpreted cautiously, as the sample size was relatively small. Some of the observed associations, however, are less likely to be due to chance. Most of the common atherosclerosis risk factors were associated with CTS among young subjects. Moreover, after correcting for multiple testing (Bonferroni correction), the associations of high LDL 
Table 6 Odds ratio of possible and probable carpal tunnel syndrome combined for each standard deviation (0.23 mm) increase in mean carotid intima-media thickness according to exposure to physical workload factors in subjects aged 45-74.

\begin{tabular}{|c|c|c|c|c|}
\hline Physical workload factor & Sample & Cases & OR * & $95 \% \mathrm{Cl}$ \\
\hline \multicolumn{5}{|l|}{ Handgrip with high forces } \\
\hline No & 979 & 26 & 1.1 & $0.6-1.7$ \\
\hline Yes & 363 & 29 & 1.5 & $1.0-2.2$ \\
\hline \multicolumn{5}{|l|}{ Manual handling of loads $>20 \mathrm{~kg}$} \\
\hline No & 1091 & 39 & 1.1 & $0.7-1.6$ \\
\hline Yes & 253 & 16 & 2.1 & $1.2-3.7$ \\
\hline \multicolumn{5}{|l|}{ Use of vibrating tools } \\
\hline No & 1233 & 49 & 1.3 & $0.9-1.8$ \\
\hline Yes & 111 & 6 & 1.4 & $0.7-2.5$ \\
\hline \multicolumn{5}{|c|}{ Handgrip with high forces and handling of loads $>20 \mathrm{~kg}$} \\
\hline None & 908 & 25 & 1.1 & $0.7-1.8$ \\
\hline Only handgrip with high forces & 182 & 14 & 1.1 & $0.5-2.0$ \\
\hline Only handling of loads $>20$ kg & 71 & 1 & - & - \\
\hline Both & 181 & 15 & 2.6 & $1.4-4.8$ \\
\hline
\end{tabular}

* Adjustment for age, gender and education

Table 5 Odds ratio of possible and probable carpal tunnel syndrome combined for joint effects of body mass index and serum lipids or hypertension in subjects aged 30-44 ( $N=2132$ )

\begin{tabular}{|c|c|c|c|c|}
\hline Characteristic & Sample & Cases & OR & $95 \% \mathrm{Cl}$ \\
\hline \multicolumn{5}{|l|}{ BMI $\left(\mathrm{kg} / \mathrm{m}^{2}\right)$ and LDL cholesterol (mg/dL) } \\
\hline $\mathrm{BMI}<25$ and LDL cholesterol $<129$ & 550 & 8 & 1 & \\
\hline $\mathrm{BMI} \geq 25$ and LDL cholesterol $<129$ & 355 & 8 & 1.5 & $0.5-4.1$ \\
\hline BMI $<25$ and LDL cholesterol $\geq 130$ & 532 & 10 & 1.2 & $0.4-3.3$ \\
\hline $\mathrm{BMI} \geq 25$ and $\mathrm{LDL}$ cholesterol $\geq 130$ & 594 & 21 & 2.7 & $1.2-6.4$ \\
\hline
\end{tabular}

BMI $\left(\mathrm{kg} / \mathrm{m}^{2}\right)$ and triglycerides $(\mathrm{mg} / \mathrm{dL})$

$\mathrm{BMI}<25$ and triglycerides $\leq 150$

$\mathrm{BMI} \geq 25$ and triglycerides $\leq 150$

$\mathrm{BMI}<25$ and triglycerides $>150$

$\mathrm{BMI} \geq 25$ and triglycerides $>150$

$\begin{array}{cccc}945 & 16 & 1 & \\ 550 & 14 & 1.5 & 0.7-3.4 \\ 137 & 2 & 0.9 & 0.2-4.7 \\ 399 & 15 & 2.9 & 1.3-6.4\end{array}$

BMI $\left(\mathrm{kg} / \mathrm{m}^{2}\right)$ and blood pressure

$\mathrm{BMI}<25$ and normal blood

pressure

BMI $\geq 25$ and normal blood

pressure

$\begin{array}{llllll}\mathrm{BMI}<25 & \text { and high blood pressure } & 27 & 1 & 2.2 & 0.2-19.0\end{array}$

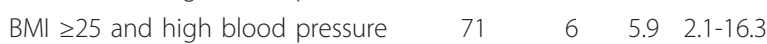

BMI $\left(\mathrm{kg} / \mathrm{m}^{2}\right)$ and insulin resistance *

$\mathrm{BMI}<25$ and low insulin resistance

$\mathrm{BMI} \geq 25$ and low insulin resistance

$\mathrm{BMI}<25$ and high insulin resistance

* Insulin resistance (serum insulin $\times$ glucose/22.5) was dichotomized using the median

Odds ratios are adjusted for age, sex, education, handgrip with high forces and work using vibrating tools cholesterol, hypertension and cardiac arrhythmia with CTS remained statistically significant in subjects aged 30-44. In those aged 45-74, the joint effect of forceful activities and thick carotid intima-media remained statistically significant. Furthermore, other comorbid conditions such as cancer, psychosis, osteoporosis, allergy, dementia and a chronic illness or inflammation of the bowel were not associated with CTS.

\section{Conclusions}

The current study may support the role of atherosclerosis and its risk factors in the aetiology of CTS. Of the two peaks in the age-specific prevalence of CTS, the first, occurring after the age of 40, may largely be due to work-related factors and the risk factors of atherosclerosis. The second peak in those aged 70 or over $[4,5,10]$, may be explained by ischemic vascular disease and atherosclerosis. Our findings suggest that CTS may be a manifestation of atherosclerosis, or that both conditions may have common risk factors. Therefore, effective population-level health promotion activities against cardiovascular risk factors may reduce the risk not only of atherosclerosis and vascular diseases, but also of CTS.
Author details

Centre of Expertise for Health and Work Ability, Finnish Institute of Occupational Health, Helsinki, Finland. ${ }^{2}$ Department of Health and Functional Capacity, National Institute for Health and Welfare, Helsinki, Finland. ${ }^{3}$ Department of Medicine, Kuopio University Hospital, and University of Kuopio, Kuopio, Finland. ${ }^{4}$ Department of Medicine, University of Turku, and Turku University Hospital, Turku, Finland. ${ }^{5}$ Unit of General Practice, Helsinki University Central Hospital, University of Helsinki, Helsinki, Finland.

${ }^{6}$ Kirkkonummi Health Centre, Kirkkonummi, Finland. 


\section{Authors' contributions}

$\mathrm{MH}, \mathrm{LM}$ and EV-J participated in the design of the study and its analysis. RS carried out the statistical analyses and drafted the manuscript. All authors critically revised the manuscript and approved the final version to be submitted for publication.

\section{Competing interests}

The authors declare that they have no competing interests.

Received: 8 September 2010 Accepted: 26 April 2011

Published: 26 April 2011

\section{References}

1. Atroshi I, Gummesson C, Johnsson R, Ornstein E, Ranstam J, Rosen I: Prevalence of carpal tunnel syndrome in a general population. JAMA 1999, 282(2):153-158

2. Walker-Bone K, Palmer KT, Reading I, Coggon D, Cooper C: Prevalence and impact of musculoskeletal disorders of the upper limb in the general population. Arthritis and rheumatism 2004, 51(4):642-651.

3. Silverstein B, Viikari-Juntura E, Kalat J: Use of a prevention index to identify industries at high risk for work-related musculoskeletal disorders of the neck, back, and upper extremity in Washington state, 1990-1998. American journal of industrial medicine 2002, 41(3):149-169.

4. Bland JD, Rudolfer SM: Clinical surveillance of carpal tunnel syndrome in two areas of the United Kingdom, 1991-2001. J Neurol Neurosurg Psychiatry 2003, 74(12):1674-1679,

5. Mondelli M, Giannini F, Giacchi M: Carpal tunnel syndrome incidence in a general population. Neurology 2002, 58(2):289-294.

6. Shiri R, Miranda H, Heliövaara M, Viikari-Juntura E: Physical work load factors and carpal tunnel syndrome: a population-based study. Occupational and environmental medicine 2009, 66(6):368-373.

7. Karpitskaya Y, Novak CB, Mackinnon SE: Prevalence of smoking, obesity, diabetes mellitus, and thyroid disease in patients with carpal tunnel syndrome. Annals of plastic surgery 2002, 48(3):269-273.

8. Solomon DH, Katz JN, Bohn R, Mogun H, Avorn J: Nonoccupational risk factors for carpal tunnel syndrome. Journal of general internal medicine 1999, 14(5):310-314

9. Shin J, Nishioka M, Shinko S, Shibuya K, Sugiki M, Kasumoto H, Fudo A, Bito Y, Fujita Y, Komaba K: Carpal tunnel syndrome and plasma beta2microglobulin concentration in hemodialysis patients. Ther Apher Dial 2008, 12(1):62-66.

10. Shiri $R$, Varonen $H$, Heliövaara M, Viikari-Juntura E: Hand dominance in upper extremity musculoskeletal disorders. J Rheumatol 2007, 34(5):1076-1082.

11. Lluch AL: Thickening of the synovium of the digital flexor tendons: cause or consequence of the carpal tunnel syndrome? J Hand Surg [Br] 1992, 17(2):209-212.

12. Sud V, Freeland AE: Biochemistry of carpal tunnel syndrome. Microsurgery 2005, 25(1):44-46.

13. Fuchs PC, Nathan PA, Myers LD: Synovial histology in carpal tunnel syndrome. J Hand Surg [Am] 1991, 16(4):753-758.

14. Kerr CD, Sybert DR, Albarracin NS: An analysis of the flexor synovium in idiopathic carpal tunnel syndrome: report of 625 cases. J Hand Surg [Am] 1992, 17(6):1028-1030.

15. Gulliford MC, Latinovic R, Charlton J, Hughes RA: Increased incidence of carpal tunnel syndrome up to 10 years before diagnosis of diabetes. Diabetes care 2006, 29(8):1929-1930.

16. Vessey MP, Villard-Mackintosh L, Yeates D: Epidemiology of carpal tunnel syndrome in women of childbearing age. Findings in a large cohort study. International journal of epidemiology 1990, 19(3):655-659.

17. Atroshi I, Gummesson C, Ornstein E, Johnsson R, Ranstam J: Carpal tunnel syndrome and keyboard use at work: a population-based study. Arthritis and rheumatism 2007, 56(11):3620-3625.

18. Nathan PA, Meadows KD, Istvan JA: Predictors of carpal tunnel syndrome: an 11-year study of industrial workers. The Journal of hand surgery 2002, 27(4):644-651.

19. Nathan PA, Keniston RC, Lockwood RS, Meadows KD: Tobacco, caffeine, alcohol, and carpal tunnel syndrome in American industry. A crosssectional study of 1464 workers. Journal of occupational and environmental medicine/American College of Occupational and Environmental Medicine 1996, 38(3):290-298.
20. Viikari-Juntura E, Silverstein B: Role of physical load factors in carpal tunnel syndrome. Scand J Work Environ Health 1999, 25(3):163-185.

21. Eshed I, Feist E, Althoff CE, Hamm B, Konen E, Burmester GR, Backhaus M, Hermann KG: Tenosynovitis of the flexor tendons of the hand detected by MRI: an early indicator of rheumatoid arthritis. Rheumatology (Oxford, England) 2009, 48(8):887-891.

22. Verdon ME: Overuse syndromes of the hand and wrist. Primary care 1996, 23(2):305-319.

23. Nakamichi $K$, Tachibana S: Hypercholesterolemia as a risk factor for idiopathic carpal tunnel syndrome. Muscle Nerve 2005, 32(3):364-367.

24. Bland JD: The relationship of obesity, age, and carpal tunnel syndrome: more complex than was thought? Muscle Nerve 2005, 32(4):527-532.

25. Balci K, Utku U: Carpal tunnel syndrome and metabolic syndrome. Acta neurologica Scandinavica 2007, 116(2):113-117.

26. Nordstrom DL, Vierkant RA, DeStefano F, Layde PM: Risk factors for carpal tunnel syndrome in a general population. Occupational and environmental medicine 1997, 54(10):734-740.

27. Giersiepen K, Eberle A, Pohlabeln H: Gender differences in carpal tunnel syndrome? occupational and non-occupational risk factors in a population-based case-control study. Annals of epidemiology 2000, 10(7):481.

28. Heistaro S, ed: Methodology report: Health 2000 Survey. Helsinki: National Public Health Institute; 2008 [http://www.terveys2000.fi/indexe.html], Accessed December, 2010.

29. Sluiter JK, Rest KM, Frings-Dresen MH: Criteria document for evaluating the work-relatedness of upper-extremity musculoskeletal disorders. Scand J Work Environ Health 2001, 27(Suppl 1):1-102.

30. Grundy SM, Brewer HB Jr, Cleeman Jl, Smith SC Jr, Lenfant C: Definition of metabolic syndrome: Report of the National Heart, Lung, and Blood Institute/American Heart Association conference on scientific issues related to definition. Circulation 2004, 109(3):433-438.

31. Shiri R, Viikari-Juntura E, Leino-Arjas P, Vehmas T, Varonen H, Moilanen L, Karppinen J, Heliövaara M: The association between carotid intima-media thickness and sciatica. Seminars in arthritis and rheumatism 2007 37(3):174-181.

32. Derogatis LR, Lipman RS, Covi L: SCL-90: an outpatient psychiatric rating scale-preliminary report. Psychopharmacol Bull 1973, 9(1):13-28.

33. Wolter KM: Introduction to Variance Estimation. New York: Springer 2 2007.

34. Geoghegan JM, Clark DI, Bainbridge LC, Smith C, Hubbard R: Risk factors in carpal tunnel syndrome. Journal of hand surgery (Edinburgh, Scotland) 2004, 29(4):315-320.

35. de Groot E, Hovingh GK, Wiegman A, Duriez P, Smit AJ, Fruchart JC, Kastelein JJ: Measurement of arterial wall thickness as a surrogate marker for atherosclerosis. Circulation 2004, 109(23 Suppl 1):|ll133-38.

36. O'Gradaigh D, Merry P: A diagnostic algorithm for carpal tunnel syndrome based on Bayes's theorem. Rheumatology (Oxford) 2000, 39(9):1040-1041.

\section{Pre-publication history}

The pre-publication history for this paper can be accessed here: http://www.biomedcentral.com/1471-2474/12/80/prepub

\section{doi:10.1186/1471-2474-12-80}

Cite this article as: Shiri et al: Associations of cardiovascular risk factors, carotid intima-media thickness and manifest atherosclerotic vascular disease with carpal tunnel syndrome. BMC Musculoskeletal Disorders 2011 12:80. 